\title{
Wpływ cyklu cieplnego na właściwości zgrzewanych wybuchowo złączy stal-aluminium
}

\section{The effect of thermal cycle on properties of explosion welded steel-aluminum joints}

\section{Streszczenie}

W artykule omówiono budowę, właściwości oraz technologię wytwarzania trójwarstwowych łączników zgrzewanych wybuchowo typu stal-stop aluminium AIMg. W łącznikach tego typu występuje połączenie stali z aluminium, które decyduje o ich właściwościach eksploatacyjnych. Szczególną uwagę zwrócono na proces spawania łączników, który może być przyczyną znaczącego spadku wytrzymałości złączy stal-aluminium. Przedstawiono wyniki badań właściwości mechanicznych (wytrzymałości na odrywanie oraz mikrotwardości) newralgicznego obszaru złączy zgrzewanych wybuchowo po obróbce cieplnej. $\mathrm{Na}$ ich podstawie podjęto próbę wyjaśnienia mechanizmów decydujących o zmniejszaniu wytrzymałości połączenia stal-aluminium pod wpływem oddziaływania cyklu cieplnego.

\section{Wstęp}

Łączniki typu stal-stop aluminium (np. stal-AlAlMg4,5Mn) uzyskane metodą zgrzewania wybuchowego przeznaczone są m.in. do łączenia nadbudówek i pokładów ze stopów aluminium z różnymi gatunkami stali.

Podstawową trudnością przy wykonywaniu takich bimetali jest wąski zakres parametrów zgrzewania, w którym uzyskać można złącza o wymaganych właściwościach. Bezpośrednie zgrzewanie wybuchowe stali ze stopami AIMg o zawartości magnezu powyżej 1,5\% do tej pory nie dało zadowalających wyników. Otrzymane bimetale cechowały się rozwarstwieniami, które prawdopodobnie były efektem parowania magnezu

Dr inż. Dariusz Fydrych, dr inż. Grzegorz Rogalski, prof. dr hab. inż. Włodzimierz Walczak - Politechnika Gdańska.

\section{Abstract}

The article presents the construction, properties and manufacturing technology of explosion welded threelayer steel-aluminum alloy AIMg transition joints. In this type of connectors, joining of steel and aluminum occurs, which determines their exploitation properties. Particular attention has been given to the process of welding of transition joints, which may cause a significant decrease in the strength of steel-aluminum welds. The results of tests of mechanical properties (ram tensile strength and microhardness) of vulnerable area of explosion welded joints after heat treatment were shown. On their basis an attempt was made to elucidate the mechanisms affecting the reduction of strength of the steel-aluminum welds due to the thermal cycle.

z nadtopionej powierzchni stopu [10]. Z tego powodu podczas zgrzewania stali ze stopami AIMg stosuje się przekładkę pośredniczącą z aluminium. Dzięki takiej technologii otrzymuje się połączenie o falistej budowie oraz bardzo dobrych właściwościach. Wysoką jakość łączników potwierdzają świadectwa towarzystw klasyfikacyjnych [10-12]. W porównaniu z tradycyjnym dwurzędowym połączeniem nitowanym łączniki wykazują większą wytrzymałość doraźną (ok. dwukrotnie) i zmęczeniową (ponad pięciokrotnie). Ponadto przewyższają połączenia nitowane odpornością na korozję (przy zastosowaniu odpowiednich powłok malarskich nie stwierdzono ubytków), mniejszą o ok. 30 $\div 50 \%$ pracochłonnością i znacznie mniejszą uciążliwością wykonania [10].

Zgrzewanie wybuchowe połączenia stal-AIMg4,5Mn z przekładką aluminiową realizuje się przy równoległym ustawieniu zgrzewanych blach. Można zgrzewać jednocześnie trzy blachy albo nastrzeliwać kolejno aluminium na stal, a potem stop AIMg4,5Mn 

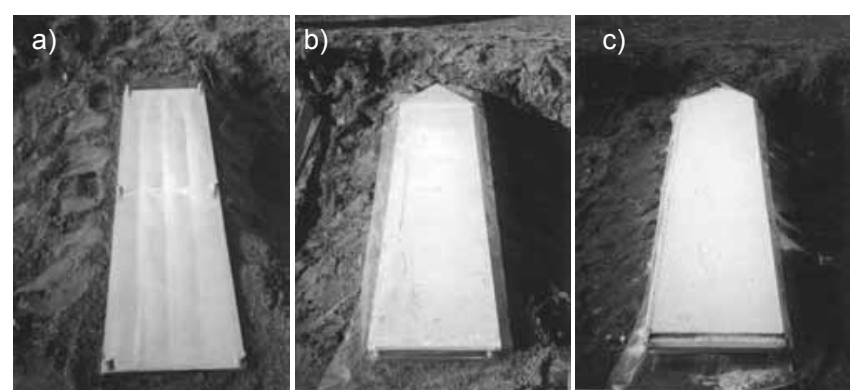

Rys. 1. Kolejne etapy przygotowania stanowiska do zgrzewania wybuchowego płyt stal-aluminium-stop aluminium: a) płyta podstawowa (stal) z kołkami dystansowymi, b) pakiet blach stal-aluminium-stop aluminium z folią zabezpieczającą oraz generatorem fali płaskiej, c) stanowisko z materiałem wybuchowym

Fig. 1. Steps of preparation of stand for explosion welding of steel-aluminum-aluminum alloy plate: a) base plate (steel) with spacer pins, b) plates steel-aluminum-aluminum alloy with protection film and plane wave generator, c) stand with explosives

na otrzymany bimetal. Pierwszy sposób jest bardziej ekonomiczny, ale trudniejszy do opanowania. Powierzchnie kontaktowe płyt stalowych powinny być obrobione przy użyciu obróbki skrawaniem, a powierzchnie płyt aluminiowych należy wytrawić kwasem fluorowodorowym w celu usunięcia warstwy tlenków. Otrzymane płyty wymagają prostowania, ponieważ ich ugięcie dochodzi do $30 \mathrm{~mm}$. Na rysunku 1 przedstawiono kolejne etapy przygotowania stanowiska do jednoczesnego zgrzewania wybuchowego trzech blach (stal-aluminium-stop aluminium).

Podczas spawania łączników istnieje niebezpieczeństwo, że w wyniku oddziaływania cyklu cieplnego spawania połączenie stal-aluminium będzie nagrzewać się do wysokich temperatur, co może niekorzystnie wpłynąć na jego właściwości wytrzymałościowe $[1 \div 3$, $6 \div 12]$. W wyniku oddziaływania ciepła w miejscu styku stali z aluminium tworzy się warstwa związków międzymetalicznych. Warstwa ta składa się przede wszystkim ze związku TeAl ${ }_{3}$, a także FeAl, $\mathrm{Fe}_{2} \mathrm{Al}_{5}, \mathrm{Fe}_{2} \mathrm{Al}_{7}, \mathrm{FeAl}_{2}$, które odznaczają się wysoką twardością $(740 \div 900 \mathrm{HV})$ i kruchością. Szerokość warstwy granicznej wynosząca od kilku do $100 \mu \mathrm{m}$ zależy od temperatury złącza i czasu jej oddziaływania [10]. Wykresy na rysunkach 2 i 3 ilustrują wyniki dotychczasowych badań. Rysunek 2 przedstawia wykresy, na podstawie których sugerowano przyjęcie temperatury $315^{\circ} \mathrm{C}$ jako temperatury granicznej, powyżej której nie powinno być nagrzane połączenie stal-aluminium podczas spawania. Wykres $z$ rysunku 3 przedstawia wyniki badań przeprowadzonych w Katedrze Technologii Materiałów Maszynowych i Spawalnictwa PG, na podstawie których również zasugerowano przyjęcie temperatury $315^{\circ} \mathrm{C}$. $Z$ wyżej podanych przyczyn technologia spawania łączników $z$ bimetalu podyktowana jest przez konieczność stosowania jak najniższej energii liniowej spawania [12].

Łączniki uzyskiwane metodą zgrzewania wybuchowego znalazły już stosunkowo szerokie zastosowanie. Jednak analiza literatury dotyczącej zagadnienia zależności wytrzymałości na odrywanie od temperatury maksymalnej spawania lub wygrzewania nasuwa

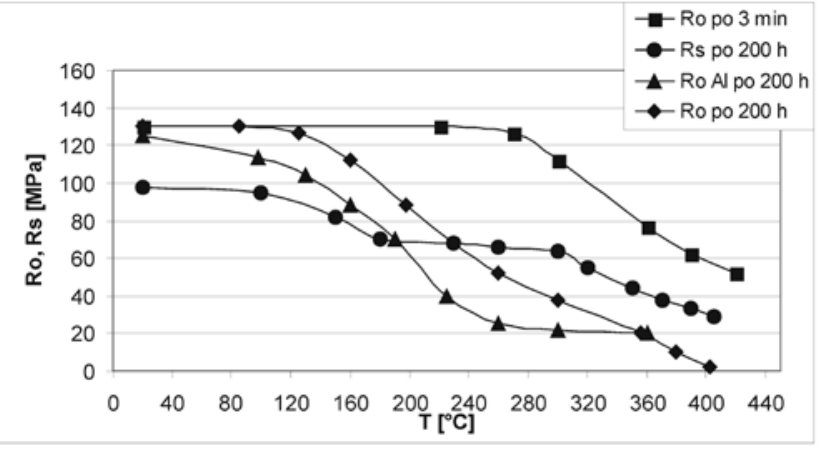

Rys. 2. Wpływ czasu i temperatury maksymalnej wygrzewania na wytrzymałość na odrywanie Ro i ścinanie Rs połączeń stal-aluminium [2]

Fig. 2. The effect of maximum heating temperature and time on ram tensile strength Ro and shear strength Rs of steel-aluminum welds

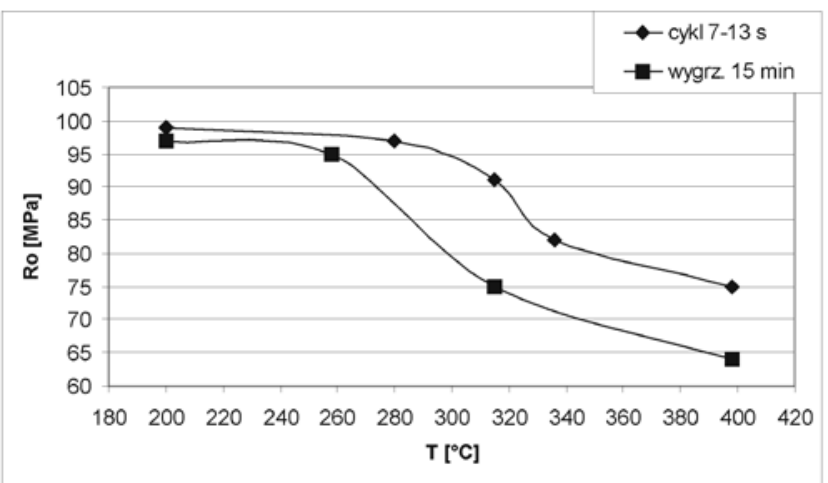

Rys. 3. Wpływ temperatury maksymalnej wygrzewania na wytrzymałość na odrywanie Ro łącznika stal-aluminium [3]

Fig. 3. The effect of maximum heating temperature on ram tensile strength Ro of steel-aluminum welds

jednak pewne wątpliwości. Odnoszą się one zwłaszcza do przyjmowania temperatury $315^{\circ} \mathrm{C}$ jako temperatury granicznej, której nie powinno przekroczyć połączenie stal-aluminium. Wydaje się, że wnioski takie sformułowano na skutek nieco bezkrytycznego przyjmowania rozrostu warstwy związków międzymetalicznych typu $\mathrm{Fe}_{m} \mathrm{Al}_{\mathrm{n}}$ jako jedynego mechanizmu odpowiedzialnego za spadek wytrzymałości połączeń stal-aluminium pod wpływem oddziaływania ciepła. Szczegółowa analiza dotychczasowych badań wyraźnie wskazuje na to, że znaczący spadek wytrzymałości połączenia jest widoczny od temperatury $280^{\circ} \mathrm{C}$.

Ponadto dodatkowe trudności przy interpretacji danych dostępnych w literaturze stwarzają różne warunki prowadzenia badań. W celu wyjaśnienia przedstawionych wątpliwości wykonano badania wpływu temperatury i czasu wygrzewania na właściwości zarówno połączenia stal-aluminium, jak i materiału przekładki $z$ aluminium $A 1$.

\section{Badania własne}

Łącznik przeznaczony do badań został wycięty $\mathrm{z}$ płyty stal-Al-AIMg4,5Mn wytworzonej metodą 
Tablica I. Właściwości wytrzymałościowe blach użytych do wykonania płyty 17R93

Table I. Mechanical properties of plates used for fabrication of $17 R 93$ plate

\begin{tabular}{|c|c|c|c|}
\hline Materiał blachy & Stan lub postać & $\mathrm{R}_{\mathrm{m}}, \mathrm{MPa}$ & $\mathrm{A} 10, \%$ \\
\hline $\mathrm{A} 1$ & $\mathrm{z4}$ & $110 \div 111$ & $\mathbf{2}$ \\
\hline AlMg4,5Mn & pgs & $440 \div 290$ & $20 \div 22$ \\
\hline \multicolumn{2}{|c|}{ Stal kategorii A } & - & 28 \\
\hline${ }^{*} \mathrm{z} 4$ - półtwardy, pgs - walcowany na gorąco, stabilizowany & \\
\hline
\end{tabular}

Tablica II. Skład chemiczny blachy ze stopu AIMg4,5Mn wg atestu

Table II. Chemical composition of AIMg4,5Mn alloy acc. to test certificate

\begin{tabular}{|c|c|c|c|c|c|c|c|c|}
\hline $\mathrm{Al}, \%$ & $\mathrm{Fe}, \%$ & $\mathrm{Si}, \%$ & $\mathrm{Cu}, \%$ & $\mathrm{Mg}, \%$ & $\mathrm{Mn}, \%$ & $\mathrm{Cr}, \%$ & $\mathrm{Ti}, \%$ & $\mathrm{Zn}, \%$ \\
\hline reszta & 0,35 & 0,26 & 0,02 & 4,49 & 0,5 & 0,14 & 0,059 & 0,017 \\
\hline
\end{tabular}

Tablica III. Skład chemiczny blachy z aluminium A1 wg atestu

Table III. Chemical composition of A1 aluminum acc. to test certificate

\begin{tabular}{|c|c|c|c|c|c|c|c|c|}
\hline $\mathrm{Al}, \%$ & $\mathrm{Fe}, \%$ & $\mathrm{Si}, \%$ & $\mathrm{Cu} \%$ & $\mathrm{Mg}, \%$ & $\mathrm{Mn}, \%$ & $\mathrm{Cr}, \%$ & $\mathrm{Ti}, \%$ & $\mathrm{Zn}, \%$ \\
\hline reszta & 0,27 & 0,18 & 0,01 & 0,02 & 0,03 & 0,01 & 0,013 & 0,006 \\
\hline
\end{tabular}

Tablica IV. Skład chemiczny blachy ze stali kategorii A wg atestu

Table IV. Chemical composition of A steel acc. to test certificate

\begin{tabular}{|c|c|c|c|c|c|c|c|c|}
\hline $\mathrm{Fe}, \%$ & $\mathrm{C}, \%$ & $\mathrm{Mn}, \%$ & $\mathrm{Si}, \%$ & $\mathrm{P}, \%$ & $\mathrm{~S}, \%$ & $\mathrm{Cr}, \%$ & $\mathrm{Ni}, \%$ & $\mathrm{Cu}, \%$ \\
\hline reszta & 0,18 & 0,67 & 0,2 & 0,034 & 0,023 & 0,14 & 0,05 & 0,07 \\
\hline
\end{tabular}

zgrzewania wybuchowego o numerze $17 \mathrm{R} 93$ i wymiarach $2000 \times 480 \times 32 \mathrm{~mm}[4,5]$. Płytę tę uzyskano zgrzewając jednocześnie blachę ze stali kadłubowej zwykłej jakości kategorii $A$ o wymiarach $2000 \times 500 \times 19 \mathrm{~mm}$ $z$ blachą aluminiową $A 1$ o wymiarach $2000 \times 500 \times 6 \mathrm{~mm}$ i blachą ze stopu AIMg4,5Mn o wymiarach $2000 \times 500 \times 10 \mathrm{~mm}$. Właściwości wytrzymałościowe zastosowanych blach podano w tablicy I, a skład chemiczny w tablicach II $\div$ IV. Ciągłość połączenia na całej powierzchni płyty poza strefą brzegową $(20 \div 40 \mathrm{~mm})$ określono na podstawie badań ultradźwiękowych.

Po wycięciu łącznika o wymiarach $2000 \times 32 \times 25 \mathrm{~mm}$ obcięto $z$ jego końców odcinki długości $300 \mathrm{~mm}$, a jego środkową część pocięto na pile mechanicznej na próbki o wymiarach $32 \times 25 \times 25 \mathrm{~mm}$. Badania podzielono na dwa odrębne eksperymenty $[4,5]$. Głównym celem takiego podziału było zbadanie wpływu różnych cykli cieplnych na właściwości połączenia stal-aluminium, a następnie aluminiowej przekładki w łączniku stal-AlAlMg4,5Mn. Pierwszy eksperyment polegał na wygrzewaniu próbek w piecu. Druga część badań polegała na punktowym podgrzewaniu od strony stali takich samych próbek palnikiem acetylenowo-tlenowym.

Próbki poddano obróbce cieplnej w zestawach składających się z 3 sztuk. Ponieważ dotychczasowe badania wskazują na niewielki spadek wytrzymałości na odrywanie pod wpływem wygrzewania w temperaturze niższej od $200^{\circ} \mathrm{C}$, maksymalna temperatura wygrzewania została wybrana $\mathrm{z}$ przedziału $200 \div 400^{\circ} \mathrm{C}$ [4]. Cykle cieplne w połączeniu stal-aluminium rejestrowano termoelementami typu $\mathrm{K}$ (NiCr-Ni). Po zakończeniu nagrzewania próbki pozostawiano do ostygnięcia w powietrzu.

Badania jakości połączenia plateru z podłożem wykonano za pomocą próby wytrzymałości na odrywanie Ro. Umożliwia ona wyznaczenie obciążenia, jakie może przenieść połączenie w kierunku prostopadłym do płaszczyzny połączenia. Próbę wytrzymałości na odrywanie przeprowadzono na próbkach standardowych przygotowanych w sposób przedstawiony na rysunku 4a, co posłużyło do oceny wytrzymałości połączenia stal-aluminium [4]. Próbę odrywania wykonano również na zmodyfikowanych próbkach przedstawionych na rysunku $4 \mathrm{~b}$, które umożliwiły zbadanie wytrzymałości na odrywanie aluminium A1 [5]. Na rysunku 5 przedstawiono zestawienie wykresów otrzymane na podstawie wyników próby wytrzymałości na odrywanie.

Dodatkowo dokonano pomiarów mikrotwardości warstwy aluminium $w$ strefie połączenia próbek niewygrzewanych oraz po obróbce cieplnej [5].

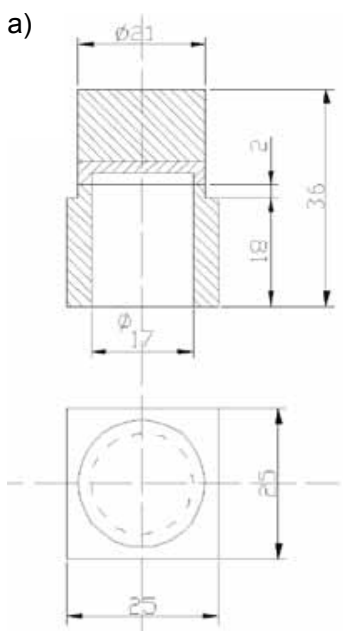

b)

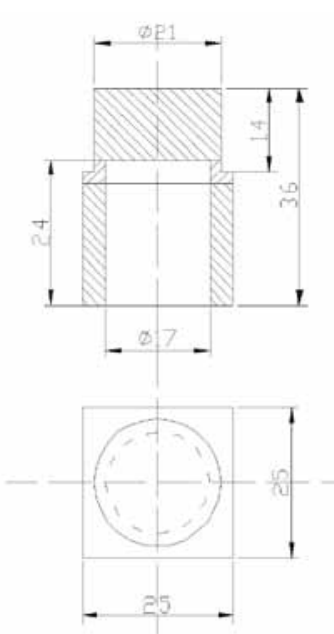

Rys. 4. Próbki do badania wytrzymałości na odrywanie $R_{o}$ : a) połączenia stal-aluminium $\mathrm{w}$ łączniku, b) warstwy aluminium $\mathrm{w}$ łączniku $[4,5]$

Fig. 4. Ram tensile specimen: a) standard for testing steel-aluminum weld, b) modified for testing aluminum layer 


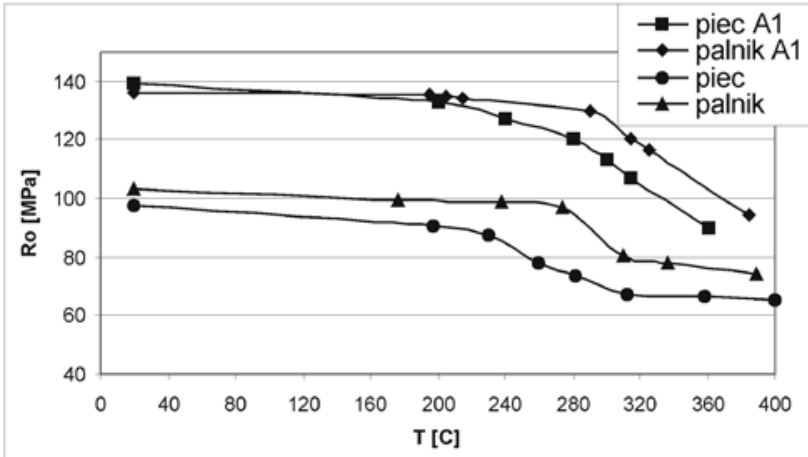

Rys. 5. Wyniki próby odrywania. A1 - wyniki uzyskane na próbkach zmodyfikowanych [5]

Fig. 5. Results of ram tensile test. A1 - results obtained on modified specimens

\section{Wyniki badań}

Wszystkie próbki wygrzewane w piecu uległy oderwaniu w aluminium. Jednak w zależności od wyglądu miejsca oderwania można je podzielić na trzy grupy. Wyniki badań wizualnych przełomów zamieszczono w tablicy V. Podobnych obserwacji dokonano podczas badań wizualnych przełomów próbek poddanych oddziaływaniu ciepła pochodzącego od nagrzewania palnikiem acetylenowo-tlenowym. W tym przypadku oderwanie wszystkich próbek nastąpiło również $w$ aluminium i wraz ze wzrostem temperatury maksymalnej $T_{m}$ cykli cieplnych plastyczność przełomów rosła. Główną różnicę stanowi brak śladów kruchych wyrwań w przełomach próbek poddanych działaniu najwyższej temperatury. Przyczyny tego zjawiska można dopatrywać się w krótkim czasie przebywania próbek powyżej temperatury granicznej.

Zależność mikrotwardości aluminium A1 od temperatury wygrzewania w piecu pokazano na rysunku 6 . Przebieg krzywej świadczy o znacznym wpływie temperatury maksymalnej cyklu wygrzewania $T_{m}$ na stan materiału przekładki.

Tablica V. Opis przełomów próbek poddanych próbie wytrzymałości na odrywanie [4]

Table 5. Description of fracture modes of specimens after ram tensile test

\begin{tabular}{|c|c|c|}
\hline $\begin{array}{l}\text { Temperatura } \\
\text { wygrzewania, } \\
{ }^{\circ} \mathrm{C}\end{array}$ & $\begin{array}{l}\text { Miejsce } \\
\text { oderwania }\end{array}$ & Uwagi \\
\hline $\begin{array}{c}\text { próbki } \\
\text { niewygrzewane }\end{array}$ & Al & \multirow{3}{*}{$\begin{array}{l}\text { przełom równomierny, bez wyraź- } \\
\text { nych śladów płynięcia materiału }\end{array}$} \\
\hline 197 & $\mathrm{Al}$ & \\
\hline 230 & $\mathrm{Al}$ & \\
\hline 260 & $\mathrm{Al}$ & \multirow{3}{*}{$\begin{array}{l}\text { widoczne ślady płynięcia materiału } \\
\text { aluminiowej przekładki }\end{array}$} \\
\hline 282 & $\mathrm{Al}$ & \\
\hline 312 & $\mathrm{Al}$ & \\
\hline 358 & $\mathrm{Al}$ & \multirow{2}{*}{$\begin{array}{l}\text { bardzo plastyczny charakter prze- } \\
\text { łomu z wyraźnymi śladami kru- } \\
\text { chych wyrwań }\end{array}$} \\
\hline 400 & $\mathrm{Al}$ & \\
\hline
\end{tabular}

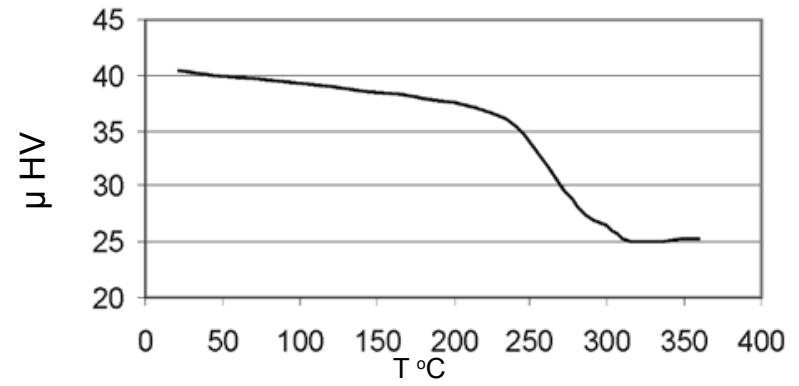

Rys. 6. Zależność mikrotwardości aluminium łącznika stal-Al-AlMg4,5Mn od temperatury maksymalnej cyklu wygrzewania w piecu [5]

Fig. 6. Results of microhardness of aluminum in steel-aluminumAlMg4,5Mn transition joint depending on maximum temperature of furnace thermal cycle

\section{Podsumowanie}

Analizując uzyskane wyniki badań można zaobserwować, że wytrzymałość na odrywanie obszaru połączenia stal-aluminium w badanym łączniku, a także jego twardość silnie zależą od wartości temperatury maksymalnej cyklu cieplnego i czasu jej oddziaływania. Potwierdza to wyniki wcześniejszych badań własnych

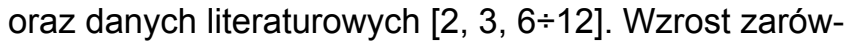
no temperatury maksymalnej poza pewną wartość, jak i czasu wygrzewania, powoduje spadek wytrzymałości obszaru połączenia. Świadczą o tym wyniki próby wytrzymałości na odrywanie próbek wygrzewanych w piecu i nagrzewanych palnikiem oraz ich bezpośrednie porównanie. Na podstawie tego ostatniego można dodatkowo stwierdzić, że przebiegi zmian wytrzymałości na odrywanie w zależności od temperatury są różne dla wymienionych sposobów nagrzewania. Przy nagrzewaniu w piecu, ze względu na dłuższy czas oddziaływania ciepła, wyraźny spadek wytrzymałości aluminium spowodowany rekrystalizacją (jak zostanie wykazane poniżej) następuje w niższej temperaturze (ok. $200^{\circ} \mathrm{C}$ ) niż przy nagrzewaniu palnikiem $\left(280^{\circ} \mathrm{C}\right)$ symulującym cykl cieplny spawania. Nie można zatem symulować zmian wytrzymałości obszaru połączenia stal-aluminium w zależności od cyklu cieplnego spawania przez wygrzewanie w piecu.

Wyniki prób wskazują, że bez względu na sposób i czas nagrzewania zniszczenie badanych próbek nagrzanych do temperatury nieprzekraczających $315^{\circ} \mathrm{C}$ nie następuje w połączeniu stal-aluminium, lecz $\mathrm{w}$ warstwie A1 przy jej wyraźnie plastycznym odkształceniu. Świadczy to o tym, że przyczyną spadku wytrzymałości obszaru połączenia nie jest spadek wytrzymałości samego połączenia, lecz zmniejszanie się wytrzymałości aluminiowej przekładki wskutek oddziaływania ciepła (rekrystalizacja). Potwierdzają to próby z wymuszonym zniszczeniem $w$ warstwie aluminium oraz pomiary mikrotwardości.

W przypadku podgrzania połączeń stalaluminium do temperatury ok. $315^{\circ} \mathrm{C}$ można zaobserwować, że zerwanie próbek nastąpiło częściowo 
w odkształconym plastycznie aluminium, a częściowo w połączeniu w postaci „kruchych wyrwań”. Zjawisko to znajduje odbicie w przebiegu zależności wytrzymałości na odrywanie od temperatury w postaci przegięcia krzywej (rys. 5). Przegięcie to nie występuje przy zależnościach wyznaczonych dla próbek z wymuszonym zniszczeniem $\mathrm{w}$ warstwie aluminium. Taki przebieg krzywych świadczy o tym, że poczynając od $315^{\circ} \mathrm{C}$ o spadku wytrzymałości połączenia współdecydować zaczyna, poza spadkiem wytrzymałości aluminium, również rozrost warstwy związków międzymetalicznych Fe-Al. Można zatem przyjąć, że w przypadku oddziaływania cyklu cieplnego spawania na połączenie stal-aluminium wyraźny spadek wytrzymałości obszaru połączenia występujący w zakresie temperatury $280 \div 315^{\circ} \mathrm{C}$ jest spowodowany jedynie spadkiem wytrzymałości aluminium. Natomiast w temperaturze wyższej od $315^{\circ} \mathrm{C}$ dalszy spadek wytrzymałości jest skutkiem współdziałania spadku wytrzymałości przekładki spowodowanego rekrystalizacją oraz rozrostu warstwy związków międzymetalicznych. Nie można wykluczyć, że pewien udział $w$ tym zjawisku mogą mieć również naprężenia ścinające wynikające $z$ różnych wartości współczynników rozszerzalności cieplnej stali i aluminium. Mechanizmy tego współdziałania wymagają jednak dalszego wyjaśnienia.

\section{Wnioski}

Wytrzymałość na odrywanie Ro obszaru połączenia stal-aluminium w łączniku stal-Al-AIMg4,5Mn zgrzewanym wybuchowo zmniejsza się wraz ze wzrostem zarówno temperatury maksymalnej $\mathrm{T}_{\mathrm{m}}$ cyklu cieplnego, jak i czasu przebywania w tej temperaturze.

W odniesieniu do cyklu cieplnego spawania wymienionych łączników silny spadek wytrzymałości Ro obszaru połączenia następuje już od temperatury ok. $280^{\circ} \mathrm{C}$ i jest spowodowany rekrystalizacja warstwy aluminium. Zatem przy spawaniu łączników dla zachowania ich wyjściowych właściwości nie należy dopuszczać, aby temperatura obszaru połączenia przekroczyła $280^{\circ} \mathrm{C}$.
W zakresie temperatur $T_{m}$ cyklu cieplnego spawania wynoszącej $280 \div 315^{\circ} \mathrm{m}$ wytrzymałość Ro obszaru połączenia stal-aluminium w łączniku maleje o $20 \div 30 \%$, przy czym zniszczenie łącznika następuje w warstwie aluminium przyległej do połączenia.

Przekroczenie temperatury $T_{m} 315^{\circ} \mathrm{C}$ powoduje dalszy spadek wytrzymałości Ro oraz zniszczenie łącznika zarówno w połączeniu, jak i w warstwie aluminium przyległej do połączenia, czego przyczyną jest współdziałanie rozrastającej się kruchej warstwy związków międzymetalicznych Fe-Al oraz malejącej ze wzrostem temperatury wytrzymałości warstwy aluminium.

\section{Literatura}

[1] Bielawski J., Krysiak E., Lewandowski B., Stolarski A., Walczak W.: Wytwarzanie łaczników bimetalowych stal-stop AlMg5. Przegląd Spawalnictwa 3/1983.

[2] Chladek L., Nemecek J., Vacek J.: Vybuchove svarovani kovu a pribuzne procesy. SNTL, Praha 1979.

[3] Dieribas A. A.: Fizika uprocznienia i swarki wzrywom. Nauka, Nowosybirsk 1980.

[4] Fydrych D.: Badania wpływu temperatury na wytrzymałość i strukturę połączeń Al-stal w łączniku stal-A1- AlMg5. Praca dyplomowa stopnia magisterskiego. Politechnika Gdańska 2000.

[5] Fydrych D., Morawiec M., Walczak W.: Wpływ temperatury i czasu wygrzewania na wytrzymałość połączeń stalaluminium w łączniku stal-A1-AIMg4,5Mn zgrzanym wybuchowo. VI Krajowa Naukowo-Techniczna Konferencja Spawalnicza „Jakość w Spawalnictwie”, Międzyzdroje, 8-10.05.2001.

[6] Leszczyński T., Polak H.: Wyznaczanie temperatury łączników St41+A1+PA11 spawanych z blachą PA11. Przegląd Spawalnictwa 5/91.
[7] Palmer T. A., Elmer J. W., Brasher D., Butler D., Riddle R.: Development of an explosive welding process for producing high-strength welds between niobium and 6061-T651 aluminum. Welding Journal 11/2006.

[8] Saperski M., Lewandowski B.: Zastosowanie łączników aluminiowo-stalowych w przemyśle okrętowym. Przegląd Spawalnictwa 7/1987.

[9] Tricarico L., Spina R.: Mechanical strength of Fe/Al structural transition joints subject to thermal loading. Archives of Materials Science and Engineering 2/2009.

[10] Walczak W.: Zgrzewanie wybuchowe metali i jego zastosowania. Wydawnictwa Naukowo-Techniczne, Warszawa 1989.

[11] Walczak W.: Charakterystyki połączeń zgrzanych wybuchowo między niektórymi metalami i stopami. Przegląd Spawalnictwa 2-3/1998.

[12] Wronka B.: Testing of explosive welding and welded joints. The microstructure of explosive welded joint and their mechanical properties. Journal of Materials Science 45 (13), 2010, pp. 3465-3469.

[13] Instrukcja spawania łączników typu stal-aluminium. Stocznia Północna SA 10/91.

Niniejszy artykuł jest rezultatem prac prowadzonych przez Prof. dr hab. inż. Włodzimierza Walczaka ze swoimi dyplomantami, a późniejszymi doktorantami i współ-pracownikami. Geneza prezentowanych wyników badań związana jest z praktycznymi aspektami głównego nurtu szkoły naukowej Profesora, zgrzewania wybuchowego. 